\title{
Paratyphoid in Man and Cattle
}

\author{
J. T. A. GEORGE， J. G. WALLACE， H. R. MORRISON， J. F. HARBOURNE
}

British Medical fournal, 1972, 3, 208-211

\section{Summary}

Salmonella paratyphi $B$, phage type Taunton, caused generalized subclinical infection of cows and cases of human enteric fever at a dairy farm. The cattle were probably infected from a stream receiving the sewage effluent of a village in which a chronic carrier lived. At the same time as the farm outbreak a water-borne outbreak of human paratyphoid fever occurred in villages several miles away. The water supply was chlorinated and no failure of its treatment had been detected. $S$. paratyphi $B$, type Taunton, was isolated from the septic tank of a cottage near the water source and from soil over a break in the effluent pipe. Several inhabitants of the cottage worked at the infected dairy farm and one showed serological evidence of infection.

Attention is drawn to the lack of statutory powers which could be applied to prevent the spread of the disease from the dairy herd and to the hazards of simple chlorination in the absence of additional safeguards of a water supply liable to pollution by surface water.

\section{Introduction}

Paratyphoid fever is usually a human disease with a human source. Authenticated outbreaks of human Salmonella paratyphi $B$ infection of animal origin are rare. This paper describes an outbreak affecting cows and personnel at a dairy farm in the North Riding of Yorkshire. A concurrent outbreak in villages six miles $(9.7 \mathrm{~km})$ away is also described. Although this outbreak was probably water-borne and not milk-borne, its origin was in the dairy farm.

The outbreaks emphasized or disclosed a number of disturbing problems, some of which indicate the need for new legislation.

\section{Outbreaks}

The human illness was enteric fever, and five cows in the dairy herd had a systemic infection with classic $S$. paratyphi $B$, phage type Taunton.

On 18 May 1970 a culture isolated from the aborted placenta of a cow was identified as $S$. paratyphi $B$. Next day a local hospital reported that one of the farm workers had paratyphoid fever. Investigation of the dairy herd started on 21 May, and the isolation of $S$. paratyphi $B$ from the milk of five cows was reported on 23 May. On 25 May two patients from a village

Medical Department, North Riding of Yorkshire County Council, Northallerton

J. T. A. GEORGE, M.D., D.P.H., County Medical Officer of Health

Public Health Laboratory, Lincoln

J. G. WALLACE, B.M., M.R.C.PATH., Director (formerly of Public Health Laboratory, Northallerton)

Health Department, Leyburn and Richmond Rural Districts, Yorkshire

H. R. MORRISON, M.B., D.P.H., Medical Officer of Health

Veterinary Investigation Centre, Ministry of Agriculture, Fisheries, and Food, Thirsk, Yorkshire

J. F. HARBOURNE, M.v.sC., M.R.C.v.S., Veterinary Investigation Officer

several miles from the farm were provisionally diagnosed as having paratyphoid fever. Further cases appeared in the same area during the days following.

The outbreaks on the farm and in the villages were investigated concurrently but are described separately.

\section{Main Human Outbreak}

Ninety cases occurred in a group of villages within an area of about 12 square miles $\left(31 \mathrm{~km}^{2}\right)$ among a population of $8,000-$ 9,000 . Most of the cases were in primary schoolchildren who fell ill between 22 and 29 May. In all cases the illness was of the enteric type; it was often mild, although 24 patients required admission to hospital. There were no deaths.

CAUSE

Milk was excluded as the vehicle of infection because the cases did not have a common supply; none received milk from the infected herd. Water was at first exonerated, as the supply to the area in which most of the patients lived was chlorinated. Moreover, satisfactory residual chlorine levels were regularly recorded at the treatment plant and in the distribution system. Water samples taken at various points on 26 May showed no evidence of faecal pollution.

Investigation of food premises, school meals, travelling shops, and ice-cream vans failed to show a common factor. Drain swabs in bakers' and butchers' shops and in an abattoir supplying most of the meat to the area were negative on culture, as was the water from local streams in which many of the children had played. Culture of faeces and serological examination of school meals staff and those preparing and serving in food premises were also negative.

The absence of any positive finding prompted a reconsideration of the water supply. Drinking water was chlorinated by a Paterson Chloronome gas chlorinator manually regulated each day. After treatment it passed into two reservoirs in parallel, having a total capacity of 300,000 gallons $(1,360,0001$.$) , which$ represented an average 24 -hour supply. The storage time during which the water was in contact with chlorine before passing into distribution was determined by the demand. Water was received at the chlorinator in underground pipes leading from the source; there was no preliminary storage or filtration. The source was several springs in a small valley, and the water was collected into small concrete and brick chambers. The immediate vicinity of the springs and chambers was enclosed.

The ground near the chambers was very marshy and it seemed possible that surface water could seep into them. At the head of the valley, 500 yards $(457 \mathrm{~m}$ ) from the enclosure, were an Army camp and a farm. The farm was disused but two cottages were inhabited. A septic tank serving the cottages discharged to a drain which also received the effluent from the camp ablution benches. This drain passed down the valley and through the spring enclosure. In view of the possibility of contamination of the water source by the septic tank effluent, and as no cause had been found for the outbreak, the water board agreed to discontinue the supply. Further investigation showed that the drain was broken at a point 50 yards $(46 \mathrm{~m})$ above the nearest spring, and the overlying ground was covered by dry sludge. $S$. paratyphi $B$, type Taunton, was isolated from the sludge and also from the septic tank.

The occupants of the cottages were three farm workers and the family of one of them. The men worked at the infected farm, 
situated 5 miles $(8 \mathrm{~km})$ away, and had been under surveillance since the initial investigation at the farm. In two of them no evidence of infection had been detected on serological examination or stool culture. The third, Mr. A., is referred to below.

Paratyphoid bacilli were not isolated from the spring waters; most samples were free of coliform bacilli, and none contained Escherichia coli. To investigate the possibility of intermittent pollution of the water source the ground overlying the broken drain was flooded with 200 gallons (909 1.) of water and fluorescein added; this flooding was augmented by heavy rainfall a few hours later. Surface water containing the dye was traced to the spring enclosure. Dye could not be detected in the spring waters entering the collection chambers, but when examined next day the majority of samples contained $E$. coli in numbers up to $160 / 100 \mathrm{ml}$.

This suggests that although paratyphoid bacilli were never actually isolated from the spring water the source was subject to faecal pollution, some of which might have originated from the septic tank serving the cottages.

\section{Farm Outbreak}

\section{HUMAN INFECTION}

Infection is believed to have occurred in 7 of the 13 persons living or working at the farm. In addition, two cases occurred in the family of one of the victims, a non-resident farm worker whose home was many miles from both the farm and the site of the main water-borne outbreak.

Of the nine persons infected three had typical enteric fever which was proved to be due to $S$. paratyphi $B$. In two others a retrospective diagnosis of paratyphoid $B$ fever was made on serological grounds; each had suffered a prolonged febrile illness in February and April 1970 respectively. Three others were found to be excreters but were either symptomless or had only trivial illness. The remaining case was that of Mr. A.

\section{INFECTION OF CATTLE AND MILK}

All animals in the herd appeared healthy; the only possible clinical evidence of infection at any time was the original abortion in May (cow No. 57).

The 59 animals in the herd were investigated by culture of individual milk samples on five occasions. Rectal swabs were taken three times and blood twice. Additional investigations were done on some animals. The initial examinations indicated that in addition to No. 57 two other cows were infected; one (No. 3) was detected by milk cultures, and the other (No. 54) by rectal swabbing. Cows 57, 3, and 54 were the only animals in which serological examination suggested infection. Two further animals (Nos. 8 and 10) became infected subsequently, $S$. paratyphi $B$ being isolated from rectal swabs and their milk; serologically both showed rising titres to $S$. paratyphi $B O$ and $H$ antigens. These results are summarized in the Table, which also shows the sites at which infection was found at necropsy.

The milk of four other cows yielded $S$. paratyphi $B$ at the first sampling, but subsequent examinations on these animals gave negative results, and it was concluded that the original culture results indicated contamination at the time of milking. The possibility of this was supported by the finding of environmental contamination. Paratyphoid bacilli were isolated from a slurry tank, from dung swabs, from the unwashed udders of several cows, and subsequently from bulked milk after all the infected animals had been removed from the herd.

The outbreak in the herd has been described in more detail by Harbourne, Randall, Luery, and Wallace (1972).

\section{CAUSE OF OUTBREAK}

The cows had access to a stream passing through the farm. $S$. paratyphi $B$, type Taunton, was isolated from the stream and from the effluent of a small sewage disposal works of conventional type discharging into the stream above the farm. The examination of upstream water was negative. A human carrier was traced in the village served by the works by means of sewer swabbing. It was later found that this person had had enteric fever, due to $S$. paratyphi $B$, type Taunton, in 1963.

METHOD OF CONTROL

\section{Milk}

The milk was already being sent in bulk for pasteurization. Boiling was advised for any consumed on the farm. After the first sampling a notice was served under the Milk and Dairies (General) Regulations 1959 prohibiting the sale for human consumption of milk from the five animals which had yielded infected milk. Two animals (Nos. 54 and 57) which were known to have systemic infection were not included in the order, as infection had not been detected in their milk, but the farmer voluntarily withheld the milk from these cows. Four animals to which the order applied were subsequently shown not to be infected. It became clear that owing to the heavy environmental contamination "uninfected" cows could-and did-yield milk that was infected from the contaminated skin of the udder. Eventually the dairy refused to accept the milk in view of the publicity associated with the infection at the farm, and the farmer had no option but to dispose of it himself. This was done by adding hypochlorite and tipping it into a hole in a field away from known water sources.

Daily culture of the bulked milk and of the filter socks frequently yielded $S$. paratyphi $B$ until 13 July, despite a

Evidence of Paratyphoid Infection in Five Cows and a Calf

\begin{tabular}{|c|c|c|c|c|c|c|c|}
\hline \multirow{3}{*}{\multicolumn{3}{|c|}{ Animal No. }} & \multirow{3}{*}{ Isolation of $S$. paratyphi $B$ during Life } & \multicolumn{3}{|c|}{ Serum Agglutination Titres } & \multirow{3}{*}{ Sites of Isolation of $S$. paratyphi $B$ at Necropsy } \\
\hline & & & & \multirow{2}{*}{ Date } & \multicolumn{2}{|c|}{ S. paratyphi B } & \\
\hline & & & & & $\mathbf{O}$ & $\mathbf{H}$ & \\
\hline 57 & .. & .. & Placenta & $27 / 5 / 70$ & $1 / 320$ & $1 / 640$ & $\begin{array}{l}\text { Lungs; hepatic, submaxillary, and retropharyngeal lymph } \\
\text { nodes; skin; udder }\end{array}$ \\
\hline 3 & . & . & Milk samples & $27 / 5 / 70$ & $1 / 320$ & $1 / 10,000$ & Udder \\
\hline 54 & . & . & Rectal swabs & $27 / 5 / 70$ & $1 / 640$ & $1 / 640$ & None \\
\hline 8 & $\cdots$ & .. & $\begin{array}{l}\text { Milk samples, rectal swabs, skin, } \\
\text { nose, conjunctiva, vagina, hooves }\end{array}$ & $\begin{array}{l}27 / 5 / 70 \\
26 / 6 / 70\end{array}$ & $\begin{array}{l}1 / 20 \\
1 / 640\end{array}$ & $<1 / 20$ & $\begin{array}{l}\text { Lungs; bile; small and large intestines; liver; vagina; uterus; } \\
\text { carpal joint; hepatic, supramammary, and mesenteric } \\
\text { lymph nodes }\end{array}$ \\
\hline 10 & .. & .. & Milk samples, rectal swabs, hooves & $\begin{array}{r}27 / 5 / 70 \\
1 / 8 / 70\end{array}$ & $\begin{array}{l}1 / 20 \\
1 / 80\end{array}$ & $1 / 320$ & None \\
\hline \multicolumn{3}{|c|}{ Calf* of Cow 8} & & $23 / 10 / 70$ & $<1 / 20$ & $<1 / 20$ & Lungs, mesenteric lymph node, nose, car, feet, placenta \\
\hline
\end{tabular}

- Slaughtered immediately after birth, before suckling. 
thorough cleansing of the farm between 11 and 19 June. A series of negative results was then obtained, and from 25 July the dairy again accepted the milk. Ironically, $S$. paratyphi $B$ was subsequently isolated from either milk samples or filters or both submitted on four of six occasions from 23 to 28 July. Since there was no evidence of infection remaining in the milking herd at the time these results were probably due to contamination from the environment at milking. Despite prolonged regular sampling, positive results were obtained on only two further occasions, on 25 September and 10 November 1970.

\section{Cattle}

The farmer voluntarily segregated animals from the herd as soon as infection was detected. It was recommended that antibacterial drugs should not be used. Three cows (Nos. 57, 3, and 54) were purchased by the North Riding County Council, slaughtered on the farm on $11 \mathrm{June}$, and removed to a rendering plant. The other two (Nos. 8 and 10) were bought by the Ministry of Agriculture, Fisheries, and Food as experimental animals and transferred to the Veterinary Investigation Centre, Thirsk.

The farmer public-spiritedly refrained from selling any other animals until 6 October 1970, by which time the Ministry of Agriculture, Fisheries, and Food advised that sale was safe. The last detailed investigation of the herd was on 7 July 1970.

\section{Farm Environment}

Cleansing and disinfection of the farm was financed by the county council and kindly arranged and supervised by the divisional veterinary officer of the Animal Health Division, Northallerton, acting as agent for the county council. The measures used have been described by Harbourne et al. (1972).

\section{Link between Outbreaks}

The probable sequence of infection in the two outbreaks is summarized in the Fig.

\section{FARM OUTBREAKS}

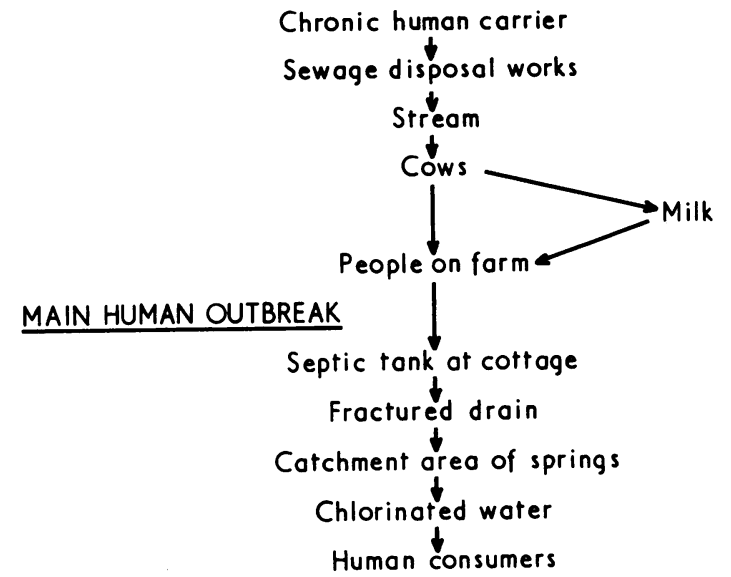

Chain of infection in outbreaks of infection with $S$. paratyphi $B$.

Mr. A. worked on the infected farm but lived in one of the cottages near the source of the water supply to the affected villages. He could therefore have been infected on the farm and could have formed the link between the two outbreaks. $S$. paratyphi $B$ was isolated from the contents of the septic tank serving his cottage, and the effluent drain was found to be fractured a short distance above the water source. His serum on 20 May showed agglutination titres against $S$. paratyphi $B$ of
$1 / 1,280(\mathrm{H})$ and $1 / 40(\mathrm{O})$. The titres were unchanged seven days later. He had not been immunized and had no history of enteric fever. Paratyphoid bacilli were not isolated from his faeces on 21 May or subsequently. He took up residence at the cottage at the beginning of May, and it is possible that he was a symptomless excreter at that time.

\section{Discussion}

\section{WATER-BORNE HUMAN OUTBREAK}

The evidence that the main human outbreak was water-borne is only circumstantial, as infection of the supply was never proved. However, the source was subject to faecal pollution, after flooding, by surface water derived from ground contaminated with paratyphoid bacilli.

Water-borne paratyphoid outbreaks are unusual even when supplies are untreated. In this instance the water was chlorinated, and residual chlorine determinations at no time indicated failure of treatment. The supply had a good bacteriological record. Coliform bacilli were not detected in any of 34 routine samples taken from the distribution system on 10 different occasions in 1970 up to and including 12 May. One of two samples on 19 May contained five coliforms per $100 \mathrm{ml}$ but no $E$. coli. No coliforms were detected in samples taken on 26 May, the day after notification of the first cases in the area. The first patient fell ill on 18 May and the majority between 22 and 29 May; this is compatible with infectivity of the water in the middle of the month. In retrospect, therefore, the finding of a few non-faecal coliforms on 19 May may have been significant, although such a result is common in rural supplies after heavy rain.

Rainfall is not recorded at the water source, but it is known that $9 \mathrm{~mm}$ fell 5 miles $(8 \mathrm{~km})$ away on 12 May. It is possible that the water source became polluted as a result of flooding of the ground on that day and that the chlorine dosage was insufficient to disinfect the water entering the distribution system at times of maximum demand.

The elimination of potential sources of contamination from the catchment area is of fundamental importance for supplies which may be chlorinated but which do not have the additional safeguards of filtration and storage before treatment. Current practice in sewage treatment cannot be relied on to kill pathogenic organisms (Working Party, 1970); both the outbreaks described confirm this. The main human outbreak resulted from the failure of a household septic tank to produce a safe effluent. The farm outbreak probably had its origin in a stream and can also be regarded as water-borne. It is clear that streams receiving effluents from conventional sewage disposal plants are a potential hazard if accessible to animals or man.

\section{PARATYPHOID B INFECTION IN CATTLE}

Salmonellas which have the antigenic structure $1,4,5,12: b: 1,2$ may be provisionally identified as " $S$. paratyphi $B$." Phage typing and tests for D-tartrate fermentation and slime wall production allow them to be classified either as true $S$. paratyph $B$, which causes enteric fever in man, or as $S$. java, which causes gastroenteritis (Kauffmann, 1955). Strains isolated from animals in the United Kingdom have usually been $S$. java (Anderson, personal communication), although they have often been recorded as $S$. paratyphi $B$ or $S$. paratyphi $B$ var. java. It has been generally accepted that true $S$. paratyphi $B$ does not infect cattle or other food animals and that these animals therefore play no part in the epidemiology of paratyphoid fever.

Milk has frequently been incriminated, not as a result of disease in cows but following the contamination of their milkby human carriers in the dairy (Ministry of Health, 1958), by the use of sewage-polluted water for washing dairy equipment (Kelman, 1944), or by contamination of the udders of cows from a polluted stream (Wallace and Mackenzie, 1947). 
In contrast, infection of cows with $S$. paratyphi $B$ var. java has been responsible for milk-borne gastroenteritis in man (Talbot, Wauchob, Robertson, and Farrell, 1967; Anderson, personal communication) and was also suspected in another investigation of cases of gastroenteritis (Kingsley Smith and Thomas, 1966; Anderson, personal communication).

In the present outbreak the strain infecting the dairy herd was identified as classic $S$. paratyphi $B$, and the associated human illness was enteric fever. This is the first known instance of infection of cattle by true $S$. paratyphi $B$ in the United Kingdom. Serological tests and necropsy proved that the infection can be generalized.

It has always been assumed that the only reservoir of classic paratyphoid bacilli is man and that infection is transmitted from man only by direct contact or through the use of sewagepolluted water in the production of milk or other foods. Salmonella food poisoning, however, from its first recognition has been associated with clinical or symptomless infection of animals at slaughter, with subsequent contamination of the carcass during dressing. It has also been recognized more recently that the transfer of infection from symptomless excreting animals to healthy ones can occur during the holding period at the abattoir before slaughter (McDonagh and Smith, 1958). While the herd was infected there was a risk that slaughter or sale of infected animals might result in the widespread contamination of meat supplies or the introduction of paratyphoid infection into other herds. These possibilities were thought to constitute a greater danger than the risk of milk-borne infection, as the milk was treated at a modern pasteurization plant.

\section{CONTROL MEASURES AT THE FARM}

\section{Milk}

The supply of infected milk for pasteurization involved some risk. Inadequate pasteurization was possible, though unlikely in a modern plant with automatic control of processing. Environmental contamination was also possible, with hazard to the workers or contamination of milk products or both. In the event, no paratyphoid infection was reported among either employees or customers of the dairy. In retrospect it is possible that the milk had been contaminated for several months, as the first human infection at the farm occurred in February 1970, and if this was the case the risk was theoretical rather than real. However, once infection had been shown it seemed advisable to minimize the risk by withholding the milk from infected animals. This was only partly successful, as it soon became clear that the milk from animals without bacteriological evidence of infection became contaminated by the normal milking procedure.

\section{Animals}

The isolation of $S$. paratyphi $B$ from the placenta of a cow in the herd, followed by the diagnosis of enteric fever in one of the farm workers, indicated an unprecedented and dangerous situation on the farm for which powers of control did not and still do not exist.

As the law stands nobody has the power to enforce the investigation and control of salmonellosis in living animals. A medical offier of health can sample bulked milk for the purposes of Regulation 20 of the Milk and Dairies (General) Regulations 1959, but he cannot enforce the investigation of individual animals or prevent their movement or sale for slaughter and subsequent human consumption. In the absence of compensation to farmers such a sale must be a tempting solution to their problems. Veterinary officers of the Ministry of Agriculture, Fisheries, and Food were unable legally to intervene on the grounds that paratyphoid B infection of cattle is not an "animal health" problem, since it is not one of the diseases to which
Section 84 (3) of the Diseases of Animals Act 1950 applies. This view was subsequently confirmed by the Ministry itself, which was advised that as a matter of law paratyphoid could not be regarded as a disease to which it was permissible by order to extend the Act.

The investigation of the herd and farm was therefore possible only with the consent and willing co-operation of the farmer. The slaughter of three infected cows, compensation to the farmer, and the disinfection of the farm were financed by the county council, which, while not admitting liability, recognized that some emergency action was necessary. The disposal of two further cows was achieved by their purchase for research purposes by the Ministry of Agriculture, Fisheries, and Food.

The Joint Committee on the Use of Antibiotics in Animal Husbandry and Veterinary Medicine, when reporting in November 1969 (Joint Committee, 1969), recognized the inadequacy of existing powers and recommended "that the Agriculture Ministers should give an appropriate veterinary officer responsibility for all infectious diseases of animals in the area, or at least all such disease as appears to threaten public health, and should grant him adequate powers to minimise spread of disease. ..."

$S$. paratyphi $B$ may cause serious illness in man. Infection of cattle by this organism can result in human infection. Infection of cattle by $S$. paratyphi $B$ should therefore be regarded as an exceptional example of animal salmonellosis which urgently demands new powers such as those recommended by the Joint Committee or some other form of combined action by the veterinary and health authorities. Such powers are, in fact, being sought in a Bill which is before Parliament at the present time.

We wish to thank Mr. T. Johnston, division veterinary officer, and his colleagues, and the late Mr. D. MacDonald; the many general practitioners, medical officers of health, physicians, and pathologists who were concerned in the outbreaks; Mr. G. D. Aspin, chief county health inspector, Mr. E. McNeil, chief public health inspector, Richmond Rural Dstrict, Mr. R. Seeds, surveyor and public health inspector, Leyburn Rural District, and their colleagues; Mr. D. H. Bannister, engineer to the Northallerton and the Dales Water Board; and Dr. A. Martin, medical officer of health, Sunderland.

We also wish to thank Dr. J. H. McCoy, director, Public Health Laboratory, Hull, Dr. E. S. Anderson, director, Central Enteric Refence Laboratory, Dr. P. B. Crone, director, Public Health Laboratory, Sunderland, and Lt.-Col. R. A. Bond, for their substantial bacteriological contribution, and our colleagues in the Public Health Laboratory, Northallerton, and the Veterinary Investigation Centre, Thirsk. We are indebted to Mrs. E. Britton for secretarial help.

Not least we should like to acknowledge the helpful co-operation of the farmer in trying circumstances.

Useful discussions were held with many colleagues in the Ministry of Agriculture, Fisheries, and Food and the Department of Health and Social Security.

\section{References}

Joint Committee on the Use of Antibiotics in Animal Husbandry and Veterinary Medicine (1969). Report, Cmnd. 4190, chapt. 10, 10, 13. London, H.M.S.O.

Kauffmann, F. (1955). Zeitschrift für Hygiene und Infektionskrankheiten, 141, 546.

Kelman, J. (1944). Health Bulletin (Edinburgh), 3, 38.

Kingsley Smith, A. J., and Thomas, K. L. (1966). Monthly Bulletin of the Ministry of Health and the Public Health Laboratory Service, 25, 219.

Harbourne, J. F., Randall, C. J., Luery, K. W., and Wallace, J. G. (1972). Veterinary Record. In press.

McDonagh, V. P., and Smith, H. G. (1958). Fournal of Hygiene, 56, 271.

Ministry of Health (1958). Annual Report of the Chief Medical Officer for the Year 1957, p. 59. London, H.M.S.O.

Working Party on Sewage Disposal (1970). Report, p. 9. London, H.M.S.O.

Talbot, I. C., Wauchob, D. W., Robertson, L., and Farrell, I. D. (1967). Public Health (London), 81, 191.

Wallace, W. S., and Mackenzie, R. D. (1947). Monthly Bulletin of the Ministry of Health and the Public Health Laboratory Service, 6, 32. 